Multidisciplinary

SCIENTIFIC JOURNAL OF MARITIME RESEARCH

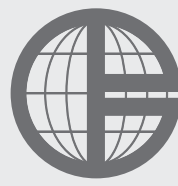

University of Rijeka

Faculty of Maritime

Studies Rijeka
Multidisciplinarni

znanstveni časopis

POMORSTVO

\title{
Organizational factors in management of "Mega Cruise Ships" from Crowd Management Control aspect
}

\author{
Damir Vukonić ${ }^{1}$, Toni Bielić ${ }^{2}$, Andrea Russo ${ }^{3}$ \\ ${ }^{1}$ University of Rijeka, Faculty of Maritime Studies Rijeka, Studentska 2, 51000 Rijeka, Croatia, e-mail: damir.vukonic@ri.ht.hr \\ ${ }^{2}$ University of Zadar, Maritime Department, Mihovila Pavlinovića bb, 23000 Zadar, Croatia, e-mail: tbielic@unizd.hr \\ ${ }^{3}$ University of Split, Faculty of Maritime Studies Split, Rudjera Boskovica 37, 21000 Split, Croatia, e-mail: arusso5@gmail.com
}

\section{ABSTRACT}

Due to the size and number of people on board, management of Mega Cruise ships is complex task, especially when managing response during emergency situations. Any emergency situation that occur on cruise ships, as a consequence will have reaction from passengers. Crowd Management Control is a process to manage this reaction. Objective of this work is to explain that management of emergency situations will be successful, if following organizational factors are accomplished: ship's crew is well trained, efficient communication is established, officer's leadership skills are developed, crew members are efficiently organized to work in teams and "Culture of Safety" is accepted by all crew members on board. Effective leaders on board cruise ships will create safety awareness of the crew members that will ensure quality response during emergency situation, which will avoid or reduce number of casualties in such situations. Above mentioned organizational factors could be used in daily operations of cruise ships, as well.

\author{
ARTICLE INFO \\ Review article \\ Received 20 May 2016 \\ Accepted 7 June 2016 \\ Key words: \\ Cruise Ships \\ Crowd Management Control \\ Emergency situation \\ Management \\ Training \\ Communication \\ Leadership \\ Teamwork
}

\section{Introduction}

In recent time, we are witnessing that very large cruise ships are being built. Their big dimensions and large number of guests and crew, represents challenge in organizing safe operations from management perspective.

At this moment, there are existing more than 60 cruise ships larger than 100,000 GT with capacity of more than 2500 passengers and crew members. Furthermore, by reviewing the new building order book, it can be noticed that there are plans for building more than 30 cruise ships larger than 100,000 GT in next 5 years. Some of those ships will have capacity carrying up to 6600 guest and more than 2000 crew members.

Expression "Mega Cruisers" is used to attract guest to very large cruise ships. For the purpose of this article, we can define "Mega Cruise ships", as cruise ships longer than 250 meters and with capacity of more than 2400 passengers.

Management of Mega Cruise ships is complex task, based on rigid organizational structure, where all responsibilities and duties are thoroughly divided.
Due to the large number of people on board, special attention has to be paid to procedures in case of emergency situations and management of such situation. Further, Mega Cruise Ships have to be managed in a way that these procedures are followed and that crew members are, at any time, ready to react efficiently in case of emergency situation.

In following chapters, several organizational factors, important in management of Mega Cruise ships during emergency situations, will be discussed and factors for optimization of these procedures will be suggested.

\section{Organizational structure of Mega Cruise Ships}

Mega Cruise ships are organizationally structured into departments. Although there are small differences between shipboard organizations on different cruise companies, generally organizational structure of Mega Cruise ships are following:

- Captain;

- Deck department; 
- Engine department;

- Hotel department;

- Entertainment department, and

- Human Resource department.

Each department is lead by head of department.

Captain is Master of the ship and is company representative and most senior ranking officer on board. The Master is at all times, responsible for the safety of the ship, passengers and crew. The Master supervises and ensures implementation of policies and procedures defined in company's Safety Management System ${ }^{1}$, as well as implementing of new procedures introduced by company. At all time, Master has responsibility and authority to take all appropriate action to deal with routine and emergency situations. Captain is not head of any department on ship, instead head of departments report to him.

Deck department is being lead by Staff captain or Deputy Captain (differences in nomenclature on some companies). Staff Captain is second in command of the ship and in charge when Master is not available. Staff Captain oversees all aspects of safety and security issues of the ship, passengers and crew. He is responsible for navigational aspects of ship's operations and watch keeping schedules and assignment of duties. Deck department senior leaders are Safety Officer, Chief Officer, Security Officer, Senior Doctor and Environmental Officer. Deck department is responsible for delivering safety trainings to the crew members and conducting guest drills.

Engine department is being lead by Chief Engineer. He has overall responsibility for all technical operations and equipment onboard the cruise ship. He is assisted by his senior officers: Staff Chief Engineer, Chief Electrical Engineer, Chief Refrigeration Engineer and Hotel Service Engineer. Their duty is to ensure that systems and equipment within every sub-division of the Engine Department are operating correctly and are maintained up to the standards of the Cruise Line Company and international regulations. Engine department, in cooperation with Deck department, is conducting any necessary maintenance of the safety equipment on board.

Hotel department is biggest department on board. Hotel Director is leader of the Hotel department. Depending on the nomenclature on the various cruise companies, some of Hotel department senior officers are: Food and Beverage Manager, Maitre-D, Guest Service Manager or Chief Purser, Chief Housekeeper, Hotel Stores Manager and Financial Manager. In addition, all concessionaires ${ }^{2}$, like Photo or Spa are part of the Hotel department. This department requires strong management structure in order to supervise entire operations.

\footnotetext{
1 International Maritime organization, IMO, has issued International Safety Management Code, ISM, which provide an international standard for the safe management and operation of ships and for pollution prevention.

2 Concessionaries are 3rd party vendor that have be given right to provide additional service to the passengers.
}

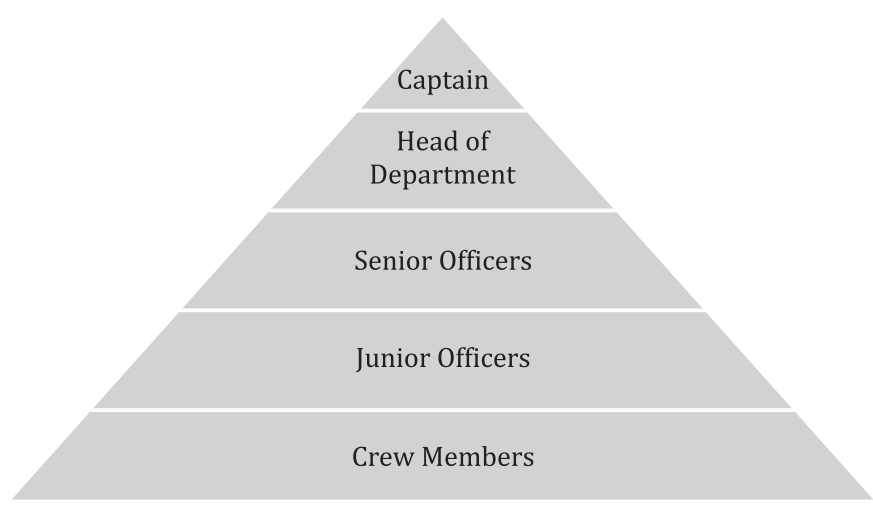

Figure 1 Cruise ship pyramidal organization Chart

Entertainment department is lead by Cruise Director. On some smaller cruise ships, Entertainment department is part of the Hotel department, but on the Mega Cruise ships, Entertainment department is autonomous department. Since guests demands for quality entertainment is higher, significance of Entertainment department is becoming stronger, and therefore Entertainment department is becoming equally important as Hotel department.

Human Resource department is responsible for employee relation, discipline measures, training of the crew members, other than safety training. Human Resource Manager is head of the department and he is working closely with Captain and Staff Captain.

Head of departments together with Captain are members of the Steering Committee. The Steering Committee is the executive leadership on the ship, responsible for setting and supervision of policy, decision making, promoting cooperation between departments and overall leadership.

Senior officers report to head of departments and are in charge of one division in the specific department. Senior officers are implementing company policy, monitor and control budget execution, supervise training schedules of the junior officers and "ordinary" crew members and supervise working schedule.

Junior officers are ship's middle management. They have control of the operations on the "floor" and are in constant contact with the "ordinary" crew members and with the passengers if they are members of hotel or entertainment department.

"Ordinary" crew members are the most numerous crew members, without officer privileges and duties, usually with small or without management tasks in their job description. If they are members of the entertainment and hotel department, they have constant contact with the passengers, for example waiters, bar tenders, cruise staff, etc.

Mega Cruise ship organization is pyramidal organization, based on hierarchy, where all duties and responsibilities are divided between various shipboard departments. Each department on board has its own hierarchical pyramidal organization. Cooperation between departments on all hierarchical levels is necessary for smooth and safe operations of the ship. 


\section{Organizational factors in management of Mega Cruise ships from Crowd Management Control aspect}

Management of Mega Cruise ships can be divided into daily, operational management and management during emergency situations. Each emergency situation that happened on board will cause reaction of the crew and passengers, which have to be well managed in order to avoid panic or injuries of crew or passengers. Cruise ships have procedures in place for dealing with large number of people on board and this is called "Crowd ${ }^{3}$ Management Control".

Crowd Management Control is application of a practical skill to control and direct crowds in an emergency situation [6]. Crowd Management on Mega Cruise ships is complex process that has to be thoroughly planned during the design of the ship. Later, during exploitation, these plans and procedures have to be strictly followed.

To achieve efficiency of Crowd Management Control procedures, continuous and repetitive education and training of crew members have to be established. It is essential that officers and crew, on all hierarchical levels, understands that repetition and continuation of training will ensure proficiency in dealing with various emergency situations.

Organizational factors in management of Mega Cruise ships from Crowd Management Control aspect are:

- management of emergency situations;

- crew members training;

- communication with passengers and crew.

In following sub-chapters this factors are discuss.

\subsection{Management of emergency situations}

During exploitation of Mega Cruise ships, it is inevitable that emergency situation of some kind will arise. Emergency situations on board cruise ships could be: collision, fire, grounding, abandon ship, medical evacuation, death, man overboard, inclement weather, security threats such as: terrorism, drug smuggling and others.

Most frequent emergency situation on cruise ships are: medical evacuations, small fires, man overboard, etc. They could be considered as operational occurrence, if they do not progress to evacuation or abandon ship. These situations could be considered as routine and well trained crew will easily deal with them. The key factor in dealing with emergency in calm and professional way is how these situations are managed. This is especially important in dealing with lethal emergency situation where loss of life or ship is foreseeable.

Management of emergency situation starts well before the moment of occurrence, by:

- establishing procedures for dealing with specific situation;

\footnotetext{
3 Cambridge Dictionary defines Crowd as a large group of people who have come together.
}

- choosing the proper crew members that will be part of the response teams ${ }^{4}$;

- training of the crew and constant improving of the procedures.

Procedures for dealing with anticipated emergency situations are published in Contingency Plan ${ }^{5}$. These procedures are to be well known to the teams that are dealing with the specific situation, especially to Command team that will lead the rest of the crew, but at the same time Command team should be aware that is not possible to predict every possible scenario that can happen in real life. Therefore, management skills of Command team members should include ability to adapt to unexpected, which can be achieved by continues training and education.

In addition to the knowledge of the emergency procedure, crew members that have assigned duties in Crowd Management Control have to have firm attitude, good selfpresentation, good leadership skills and sense of responsibilities toward the passengers in order to ensure that passengers have faith in them based on their uniform and their verbal and non-verbal behavior.

Majority of the crew members assigned to crowd management duties are from hotel or entertainment department and their nature of interaction with the passenger is more service oriented. They are used to indulge passengers and make them happy. Their attitude toward the passengers has to change at the moment of the sounding of emergency alarm. They have to assume role of the leader and enforce their authority over the passengers. These crew members have good ability to communicate with the passengers during an emergency situation and that is contributing factor for assigning them to Crowd Management Control duties.

Crew members have to be encouraged to share any information or opinion pertaining to emergency situation with their leaders. This can help in preventing or reducing development of unwanted events, especially when dealing with security threats. It is important that leaders on board cruise ships develop "culture" that everyone is welcomed to share their opinion and information without being punished or embarrassed.

\subsection{Crew members training}

Training of crew members on the Cruise ships is divided into three parts:

- On job training - is performed on actual work location and will provide to crew member necessary knowledge and skills to efficiently perform work that he or she is hired for;

\footnotetext{
4 Team is a group of people with a full set of complementary skill required to complete a task, job, or project [14]. Response teams are dedicated teams that will act in certain emergency situations like: Command Team, Fire Team, Stretcher Team, Air bottle Team, Technical Team, Evacuation team, etc.

5 Contingency Plan is part of Ship's Safety Management System where procedures for dealing with various emergency situations are developed. Contingency Plan has to be available to all crew members.
} 
- Human Resource trainings - introduce company policy and rules of behavior on board cruise ships;

- Safety trainings and drills - are ensuring that crew members are performing their duties efficiently during emergency situations.

In this article focus will be on the Safety training and drills.

Difference between safety trainings and safety drills has to be determined.

During Safety trainings, crew members are learning techniques and procedures for dealing with specific emergency situation. Number and type of safety trainings can vary due to level of crew member's performance or number of new crewmembers that recently joined the ship. If the Cruising Company is authorized by flag state to provide trainings in accordance with STCW [7] convention, then Safety trainings will be provided to the crew members that do not have required STCW certificates. Safety trainings are provided to smaller group of people or to single response teams. For example, members of one fire team could be trained in firefighting techniques.

Safety drills incorporates large number of crew members at the same time. Crew members practice knowledge obtained during safety trainings, they practice work in teams and coordination between teams. For example, firefighting safety drills will include all Fire Teams, Search and Rescue Team, Command Team, Medical Team, etc. SOLAS convention [8] regulates minimum frequency of Safety drills, which can be increased if needed. Purpose of Safety trainings and drills is to increase crew member performance during emergency situations.

The level of crew member performance can be distinguished by three levels of behavior [11]:

Knowledge based behavior, which occurs at the level of learning, has no pre-packaged solutions available for new situations. Crew members are forced to engage in conscious thought to develop these solutions. This slows performance down, as tasks can only be completed one at a time and as a series of steps. Crew members on this level can be perceived as uncertain and afraid and cannot provide proper leadership to the passengers in case of emergency.

Rule based behavior is an intermediate way of carrying out tasks where crew members have learned the procedures and, if faced with a new situation, can bring to conscious thought some already trained solutions stored in their memory. In the event that the cause of the problem cannot be established by applying any available rule, the crew member may then have to revert to the knowledge based level. The first strategy likely to be applied is to attempt to find an analogy between the unfamiliar situation and some of the patterns of events for which rules are available at the rule based level. If such a diagnostic rule can be found which validly applies, the crew member will revert back to the rule based level and use the appropriate action rule [3]. However, if a suitable analogy cannot be found, crew members will feel uncertain in their ac- tions and may feel fear, which can progress into state of panic. In this state, they cannot handle emergency situation. Generally, crew members on Rule based behavior level can provide solid performance and keep control in case of emergency if they are well trained in various different scenarios.

Skill based behavior represents highly developed learning. At this level, tasks have been learnt and practiced to such a high degree of proficiency that they become almost routine. Many tasks can be carried out at the same time, and in parallel, with little conscious thought. It is recommended that crew members on this level of behavior are assigned as leaders in case of emergency, because they can have strong, ensuring attitude to the passengers and at the same time they can provide guidance to other crew members.

The Manila Amendments of the International Convention on Standards, Training, Certification and Watch keeping for Seafarers (STCW), 1995, Regulation V/2, section $\mathrm{A}-\mathrm{V} / 2$ define mandatory training requirements and qualifications for masters, officers, ratings and other personnel on passenger ships. As per STCW 1995, each person that is employed as crew member on board the passenger ship has to have Certificate of proficiencies in Crowd Management Control and Crisis Management [7]. These trainings could be obtained in maritime training centers that provide "Crowd Management Control courses", based on the guidelines from IMO Model Course 1.28 [6].

These courses are tailored to provide familiarization and basic knowledge that can be applied on any passenger ship in the world; therefore, specific on board training has to be held as soon crew members join the ship.

Crew members that are joining cruise ships for the first time in their life might have difficulties to comprehend complexity of the Crowd Management Control on board big cruise ships.

If Flag State approve Cruise Company to provide Crowd Management control courses, Certificate of proficiency in Crowd management Control could be obtain on board cruise ship. In this case, new crew members are trained in Crowd management control techniques according to IMO model Course 1.28. Advantage of obtaining certificate on board is that crew members are trained on the ship where they are working, which will help them to understand their duties.

Crew members' Safety trainings are starting with the first day of joining on the ship with safety familiarization of the ship. Safety familiarization training is the best opportunity to stress the importance of the safety on the ship and gives the first impression to the newly joined crew members. Crew members will easily remember attitude and knowledge shown by trainers on their first day on board and will carry this impression for a while. Therefore, it is essential that qualified officers conduct Safety familiarization training in highly professional manner.

On board Crowd Management Control training, consist of theoretical and practical part. Theoretical component of the training can be accomplished through regular class 
trainings. These trainings can be held in class room or in the area of the ship where certain Response team is designated to act.

Practical part of the on board Crowd Management control training is accomplished through numerous passenger and crew drills. Depending on the ship itinerary, passenger's drills can be held even every 3 to 4 days, which will ensure that crew members that have assigned duties in passenger areas are well familiar and trained in evacuation procedures.

Training of the crew members in crowd management should be conducted in frequent intervals and throughout their stay on board, which will ensure that crew members achieve "Skill based" behavior. It is essential that crew members are working in the teams and that they feel connection with other team members. Once the cohesion of the team is achieved, team will perform well during the drills, but also during the actual emergency situation.Only very well trained crew members can efficiently and consistently provide high quality work.

\subsection{Communication with passengers and crew}

In dealing with emergency situation, communication is essential tool; therefore, special attention has to be given to the communication techniques during crew members training.

Mega cruisers have crew compliment up to 2000 members, coming from many different countries (on some ships there are more than 50 nationalities), therefore it is essential that all communication be conducted on language known to everyone. For that reason, official working language on Mega cruisers must be English language.

National diversification of the passengers can be even bigger than crew diversification, which is another reason that English language should be official language on board Mega Cruisers. In case of emergency situation, all communication with passengers and crew has to be in English, but additional communication with the passengers can be on the Spanish, Italian, Chinese, or any other language, depending on the ethnicity of the passengers. The most efficient way to communicate information efficiently to the passengers is that public announcement from the Bridge include announcements on the English and one other predominant language.

For example, when cruise ships are sailing in certain trading areas such as Caribbean or Bahamian area, with departures from Miami, it is common that majority of the passengers only speaks Spanish; therefore, it is beneficial that public announcement during Passenger drills ${ }^{6}$ and real emergency situations are in English and in Spanish language.

\footnotetext{
6 According to SOLAS convention [8], passenger drills have to be conducted before departure from the passenger's embarkation port. It consist of assembling and counting of all passengers on dedicated Assembly stations, demonstration of donning of life jackets and demonstration of life saving appliances.
}

In addition to verbal communication, there is a written communication with passengers in a form of posted directional signs, evacuation information on the cabin doors and hand held signs. These signs should be in English language.

During emergency situation crew members have to communicate clearly, correctly and in regular intervals in order to influence the people. Depending on the goal that has to be achieved (calm the passenger, or direct them to move to certain area), they have to use different styles of communication. They have to provide correct and precise information to the passengers, which they received from Command team. Communication between Command team and crew members dealing with the passengers, have to be correct, precise, truthful and timely given.

Information flow between Command team and Response teams can be verbal and written communication. Verbal communication can be distorted and interrupted due to technical or non-technical barriers. Non-technical barriers are language, cultural, knowledge or personal barriers. Technical barriers could be weak, lost or interrupted radio signal, surrounding noise, lack of power, etc. Due to difficulties in communication, information or part of information can be lost, however this issue can be resolved by trained personnel who will immediately change to other means of communication such as runners, phones, different radio channels, signs, hand signals or any other mean that can help to relay information.

Written communication between Command team and Response teams can be electronical, such as use of tablets, or traditionally paper information. Electronic tablets provide real time information of the passenger count, missing people, need for additional lifejacket and request for evacuation of disabled passengers. They can even provide real time information of location of specific response teams.

Communication during emergency situations, between Command team and Response teams and between crew and passengers, is essential for efficient dealing with emergency situation. Communication has to be based on the mutual trust that was established during drills and interaction between crew and passengers, well before occurrence of emergency situation.

\section{Optimization of organizational factors in management of Mega Cruise ships from Crowd Management Control aspect}

Although, majority of the Mega Cruise Ships are well managed, accidents and incidents are occasionally happening, therefore there is room for optimization of organizational factors in management of Mega Cruise Ships.

Organizational factors in management of Mega Cruise Ships from Crowd management Control aspect can be optimize by:

- Optimization of training;

- Improving leadership techniques;

- Reducing of Human Error by developing Teamwork. 
Authors recognize above-mentioned optimization elements as the most important elements in efficient management of cruise ships. These elements have been discussed in following sub-chapters.

\subsection{Optimization of training}

Shore maritime training centers provide Crowd Management Control courses as per IMO model Course 1.28 [6]. Although, many of training centers have serious and professional approach and provide quality training, crew members that join cruise ships for the first time in their life, need to get additional training on board, once they are familiar with the ship and ship's organization. It is wrong to assume that only attendance of the one course in maritime training centers can give enough knowledge to the crew members to perform efficiently duties during emergency situation.

For the same reason, crew members that recently joined cruise ships for the first time in their life should not be assigned duties in emergency situation, before they are well familiar with the ship, procedures and tasks they have to perform. This is guidance to the Safety Officers, or the officers who are assigning safety duties to the crew members, to ensure that level of proficiency which particular crew members has, is adequate to the requirements of assigned duty. Regardless of "commercial pressure", crew members have to be properly trained and ready to be assigned to specific duties.

Safety trainings have to cover various scenarios so the crew members could be well trained in different situation that can happen, but in addition crew members have to be prepared that unexpected scenarios could occur in real life, and they have to "think out of box" in order to deal with specific emergency situation. This can be achieved only by continuous and repetitive safety training where numerous different scenarios and situations will be covered.

Opposite to the crew members on cargo ships, where majority of the crew are maritime seasonal professionals who had numerous safety trainings and drills in their professional life, crew members of the cruise ships, employed mainly in the hotel and entertainment department, frequently do not have previous professional experience. Due to the large number of crew members and their inexperience in dealing with emergency situation on board cruise ships, safety trainings and drills have to be frequently conducted.

Repetition of Safety trainings is essential for achieving conscious and quality reaction of crew members during emergency situation. Repetitive safety trainings of newly joined crew members have to be introduced shortly upon their joining the ship, in order to shorten time until they are ready to quality perform their duties in case of emergency situations. Continuation of safety training, meaning that crew members have to have periodic safety trainings throughout their stay on board, will ensure that level of their behavior and readiness will not decrease toward the end of their stay on board.
Cruise ships companies through their on board management have to ensure that trainers, mainly deck officers, have good knowledge and are proficient in usage of safety equipment. Officers that are teaching safety classes should attend some kind of 'Train the trainer' courses. 'Train the trainer' courses, held in maritime training centers on shore, provide familiarization with various methods of teaching. Proficiency in teaching methods is increasing quality of the safety classes. Training of the training officers is equally important as teaching of "ordinary" crew members, because if they provide incorrect information to the crew members during safety classes, that can lead to serious and dangerous situations.

In order to optimize training of the crew, senior leaders, such as Safety Officer or Staff Captain have to supervise periodically training classes and teaching skills of the training officers. Training officers have to be thoroughly evaluated before being assigned to teach a safety class.

Crew members' attendances of the safety training have to be mandatory. Some companies are using repressive methods to make sure that attendance of safety training is taken seriously by crew members and their department leaders. If leaders have serious approach to the safety and safety trainings, crew members will follow these leaders and adopt their approach and will have positive attitude toward safety trainings.

\subsection{Improving Leadership techniques}

On cruise ships, senior and junior officers are not just managers, they are leaders in their respective department. Since they are not born with leadership skill, their leadership skills have to be developed.

There are several definitions of leadership. As per William Glasser, Leadership is a skill of the management of workers in a way that they provide high quality work with low cost [4]. Martin Chemers define leadership as: "a process of social influence in which a person can enlist the aid and support of others in the accomplishment of a common task" [1]. Another definition from Glasser can be adapted from Crowd management aspect, as skill of influencing on the people (passengers and crew) to follow instructions from the leader and to act according to established emergency procedures [4].

Efficient leadership in emergency situations on Mega Cruisers is important due to the number of people on board and lack of efficient leadership can be lethal. One of the most famous examples of lack of leadership with lethal consequences, in the recent history, has happened during the disaster of Costa Concordia, occurred on January $13^{\text {th }}$ 2012. As per marine casualty investigation report [9], there were more officers, beside the Master, such as Hotel Director and Deck Officers that did not react as per assigned duties and they did not provide required leadership in emergency situation.

Depending on the personality and experience of the leader, common leadership styles on board cruise ships are [13]: 
- Autocratic leadership style, and

- Participative or Democratic leadership style.

Traditionally on the ships, autocratic leadership style is common among the captains, deck and engine officers. In autocratic leadership style, leaders prefer to retain authority, they are task oriented and expect from team members to comply with their decision. Autocratic leaders typically make choices based on their ideas and judgments and rarely accept advice from subordinates. The autocratic leadership style is best used in situation when control is necessary and when there are little margins for error, such are emergencies on board Mega Cruise Ships. When conditions are dangerous, following of strict rules is beneficial. Downside of Autocratic leadership style is that subordinates may dislike that they are unable to contribute ideas. Autocratic leaders may overlook the knowledge and expertise of the team members, which might result in poor performance of the entire team. Autocratic leaders could be effective and efficient if they respect their subordinates, explain the rules, keep consistency, educate subordinates before they enforce decision and are listening opinion from subordinates, even if they do not change their decision.

In Participative leadership style, also known as Democratic leadership style, leaders make decision after consultation with team members. Participative leaders encourage team members to participate but retain the final say in the decision-making process. Team members feel engaged in the process and are more motivated and creative. Participative leaders tend to make followers feel like they are an important part of the team, which helps foster commitment to the goals of the group [2]. Participative leadership style is one of the most effective styles and leads to higher productivity and better contribution from the crew members. Participative leadership style is base for creating strong and dynamic teams that could efficiently work in dynamic environment.

Although Participative leadership style is more efficient in daily operations on the cruise ships, it might not be effective in case of emergencies and Crowd Management Control when strong and direct leadership is needed. Therefore, leaders on Mega Cruise ships that have duties in emergency situations, have to have ability to switch between participative and autocratic leadership style when needed.

Cruising companies, mainly from USA, under influence of W.Glasser and W.E.Deming theories [4], are adopting and teaching managers new leadership style, where leader should "Lead by example" or "Lead by guidance". Primary goal of this leadership style is to guide the crew members to work efficiently and quality, together with their leaders as part of the inclusive team. By achieving this goal, crew members will feel admired and recognized for their work and will invest more effort to increase work quality. This leadership style requires more effort from the leader, because frequent interaction with the crew and "open door policy" takes a lot of leader's time. Further, it is taking a long time until crew members will accept leader as supportive person and will be willing to share with him their ideas and opinions. On the other side, once this mutual trust and interaction are achieved, team performance improves.

Trust between leaders and team members have to be established long before emergency situation arose. This can only be achieved if leaders, during daily operations, are showing positive attitude toward safety, safety trainings, and drills and genuinely taking care of their crew members' safety. If leader has negative attitude toward the coming safety drill and is expressing negative opinion in front of crew members before the drill, it is reasonable to expect that crew members will show negative attitude during the safety drill, as well. Leaders have to act opposite and create "Culture of Safety".

"Culture of Safety" is taking care of crew members' safety in daily operations, during the working hours and after working hours. Crew members will copy leaders' behaviors and will start to take care of their own safety and safety of their fellow crew members. Goal is to achieve that crew members follow safety procedures, not because it is mandatory as per company procedures, but because they feel good to adopt and follow safety procedures.

Mega Cruise Ships could have crew compliment consisting of more than 50 nationalities. Managing of such international organization involves understanding of different national cultures, where communication is one of the primary concerns. Cross-cultural communication requires being aware of cultural differences, because what may be considered perfectly acceptable and natural in one country can be confusing or even offensive in another [5]. Cruise companies have to provide training to the officers on board cruise ships to make them sensitive to cultural differences of their crew members.

One of the biggest opportunities in improving leadership techniques on Mega Cruise ships is to achieve that all officers become leaders, who take care of their crew members and passengers in daily operations and in emergency situation. This cannot be achieved over night and require constant support from cruise company top management in order to provide necessary resources in a view of training programs, training classes, lecturers and supervision.

Once the leaders accept concept of "Culture of Safety", they will be more eager to spread culture among their subordinate crew members. Eventually crew members will adopt "Culture of Safety" as their own culture on board, which can certainly help in dealing with emergency situations and even preventing them.

\subsection{Reducing of Human error by developing Teamwork}

Human error is most significant cause of the majority of accidents that are happening on Cruise ships.

Human errors can be divided according to the cause to [10] [13]: 
- Poor judgment, meaning: situational unawareness, inadequate or lack of risk assessment, use of incorrect information;

- Inattention, meaning: omitting to perform the necessary attention to the available information, doing something improperly, negligence;

- Ineffective Supervision, meaning: not enforcing the procedures established by the company, inadequate oversight of operations and inadequate work quality control.

Human error can be reduced and/or prevented when individuals are working in teams. Due to delegation of workload and effective communications, efficient team can prevent errors of individual team members.

Effective communication within team members has to be structured in a form of triangle, meaning that experienced team member and their leader will monitor performance of new team member. At the same time leader will supervise experience team member and experience team member will supervise actions of leader. In this way, there is constant control of actions done by all team members, including leader, which is resulting in reduction of human error.

Team members operate with a high degree of interdependence, share authority and responsibility for self-management, are accountable for the collective performance and work toward a common goal. A team becomes more than just a collection of people when a strong sense of mutual commitment creates synergy ${ }^{7}$, thus generating performance greater than the sum of the performance of its individual members [14].

On Mega Cruise ships, there are almost no tasks that can successfully be completed without teamwork, especially not complex tasks, as it is Crowd Management Control. As previously explained, cohesion of the team should be established way before any emergency situation arose and should be constantly worked on.

Team members are frequently changing, because crew members are leaving for vacation and new crew members are joining the ship. It is common that Mega Cruise ships weekly change from 80 to $100 \mathrm{crew}$ members. Frequent crew change is affecting all teams and all departments, because they have to constantly train new team members. Frequent crew change of emergency response teams and security teams, can influence safety and security of the ships. Senior officers of each department have to be responsible and eager to organize training of newly joined crew members and support their integration into teams.

During emergency situations, it is important that each team member knows exactly who other team members are, their duties and their location, therefore safety trainings should be structured in a way to support teamwork.

\footnotetext{
7 Synergy is a state in which two or more things work together in a particular fruitful way that produces an effect greater than the sum of their individual effects. Expressed also as "the whole is greater than the sum of its parts."
}

Critical period for effectiveness of Response Team is from the moment when team leader leaves the ship for vacation until new team leader is proficient in assigned role. Rather than waiting for the scheduled drill, Safety officers should schedule additional training soon after new Response Team leader is assign to leader's duty, regardless if he or she has been assign to this duty during previous contract on board. This procedure will ensure that team members will make a link with new team leader and create mutual commitment, making team ready to efficiently react in case of emergency situation.

Cruise companies frequently practice "back to back" crew change policy, meaning that crew members are returning to the same ship after vacation. This policy ensures continuity and significantly shortens time needed for acclimatization of newly joined crew member.

Developing of teamwork is important organizational factor in optimization of management of Mega Cruisers, because teamwork is a method of reducing human error and increasing work quality and efficiency. Department leaders and their senior officers, who are responsible for creating teams and their development, have to understand importance of teamwork and importance of communication structured in form of triangle. Department leaders have to emphasis team development.

\section{Conclusion}

Mega Cruise ship organization is pyramidal organization, based on hierarchy, where all duties and responsibilities are divided between various shipboard positions. Each department on board has its own hierarchical pyramidal organization. Cooperation between departments on all hierarchical levels is necessary for smooth and safe operations of the ship.

Due to the size and number of people on board, management of Mega Cruise Ships is complex task that depends on several organizational factors such as:

- training of the crew members,

- communication techniques among crew members and between crew members and passengers,

- leadership skills of officers on board,

- teamwork.

Crew members training is the most important organizational factor in management of Mega cruise Ships because only very well trained crew members can efficiently and consistently provide high quality work.

In order for crew members to perform efficiently during emergency situations, they have to pass through numerous and frequent safety trainings and drills. It is wrong to assume that attendance of Crowd management Control Course in maritime training centers ashore is enough to perform efficiently duties during emergency situations. Crew members have to be additionally trained, starting from the first day on board and continued throughout the rest of the crew members stay on board ship. 
Safety trainings have to be professionally developed and delivered, therefore education of trainers have to be considered seriously. Officers that are performing these trainings have to be properly evaluated before starting to teach safety classes. It is beneficial if "Train the Trainer" courses in maritime training centers on shore, can be arranged for all officers that are delivering safety trainings.

Communication during emergency situations is essential for efficient dealing with such situations. Communication has to be based on the mutual trust that was established during drills and interaction between crew and passengers, well before occurrence of emergency situation. All communication has to be in English, but in addition, there could be announcements from the Bridge on additional language beside English, if ethnicity of passengers on board is such.

One of the biggest opportunities in improving of leadership techniques on Mega Cruise ships is to achieve that all officers become leaders who take care of their crew members and passengers, in daily operations and in emergency situation. This cannot be achieved over night and require constant support from cruise company top management in order to provide necessary resources in a view of training programs, training classes, lecturers and supervision.

Once the leaders accept concept of "Culture of Safety", they will be more eager to spread culture among their subordinate crew members. Eventually, crew members will adopt "Culture of Safety" as their own culture on board, which will result in reduction of incidents and accidents on board and better efficiency in dealing with emergency situations.

Streaming for constant improvement of training, communication techniques and leadership styles is only way to optimize management of Mega Cruise Ships.

\section{References}

[1] Chemers, M. M.: An integrative theory of leadership. s.l.: Lawrence Erlbaum Associates, 1997. ISBN 978-0-8058-2679-1.
[2] Cherry, K.: http://psychology.about.com/od/leadership/f/ democratic-leadership.htm. [Online]

[3] Embrey, D.: Understanding Human Behaviour and Error. s.l. : Human Reliability Associates 1, School House, Higher Lane, Dalton, Wigan, Lancashire. WN8 7RP.

[4] Glasser, W.: The Control Theory Manager. s.l. : Harper \& Collins Publisher, Inc, 1994.

[5] Hofstede, G.: Culture's Consequences: International Differences in Work-Related Values, 2nd ed. Beverly Hills, CA: SAGE Publications, 1984. ISBN 0-8039-1444-X.

[6] IMO, Model Course 1.28 "Crowd Management, Passenger Safety and Safety Training for Personnel Providing Direct Services to Passengers in Passenger Spaces. s.l.: IMO, 2010.

[7] IMO, International Convention on Standards of Training, Certification and Watchkeeping for Seafarers (STCW) as amended, including the 1995 and 2010 Manila Amendments. s.l.: IMO, 2010.

[8] IMO, International Convention for the Safety of Life at Sea (SOLAS), 1974, s.l.: IMO.

[9] Ministry of Infrastructures and transports, Italy, Marine Casualties Investigative Body. Report on the safety technical investigation on Cruise Ship Costa Concordia, Marine casualty on January 13, 2012, 2012.

[10] Reason, J.: Human Error. s.l.: Cambridge University Press, 1990. ISBN 978-521-31419-0.

[11] Reason, J.: Managing the Risks of Organisational Accidents, Taylor and Francis, 2016 ISBN 978-1-84014-104-7.

[12] Russo, A., Urlic, I. and Kasum, J.: Human resources and their possible forensic meanings. Psychiatria Danubina, Medicinska naklada, Zagreb, Croatia. 2015, Vol. 27.

[13] Vessel Resource Management Simulator Course. s.l.: STC B.V., 2011. Version 1.1.

[14] http://www.businessdictionary.com/definition/team. [Online]

[15] https://disneycruise.disney.go.com/. [Online]

[16] https://www.carnival.com/. [Online]

[17] https://www.ncl.com/. [Online]

[18] https://www.princess.com. [Online]

[19] https://www.royalcaribbean.com/. [Online] 